\title{
Communication
}

\section{Intramolecular Metal Exchange Reaction Promoted by Thiol Ligands}

\author{
Yangfeng Li, Man Chen, Shuxin Wang * and Manzhou Zhu * \\ Department of Chemistry and Centre for Atomic Engineering of Advanced Materials, Anhui Province Key \\ Laboratory of Chemistry for Inorganic/Organic Hybrid Functionalized Materials, Anhui University, \\ Hefei 230601, Anhui, China; 18255127378@163.com (Y.L.); 13101@ahu.edu.cn (M.C.) \\ * Correspondence: Ixing@ahu.edu.cn (S.W.); zmz@ahu.edu.cn (M.Z.); Tel.: +86-551-63861487 (S.W. \& M.Z.)
}

Received: 29 November 2018; Accepted: 13 December 2018; Published: 19 December 2018

\begin{abstract}
The synthesis of an alloy nanocluster that is atomically precise is the key to understanding the metal synergy effect at the atomic level. Using the $\mathrm{Ag}_{2} \mathrm{Au}_{25}(\mathrm{SR})_{18}$ nanocluster as a model, we reported a third approach for the metal exchange reaction, that is, intramolecular metal exchange. The surface adsorbed metal ions (i.e., Ag) can be exchanged with the kernel metal atoms (i.e., Au) that are promoted by thiol ligands. The exchanged gold atoms can be further stripped by the thiol ligands, and produce the $\mathrm{Ag}_{x} \mathrm{Au}_{25-x}(\mathrm{SR})_{18}{ }^{-}$nanocluster.
\end{abstract}

Keywords: alloy; metal exchange; atomically precise

\section{Introduction}

Precise alloy nanoclusters have recently attracted great interest due to their quantum size effect-induced unique optical and catalysis properties [1,2]. More importantly, with their well determined structure, the relationship between their structure and properties can be grasped at the atomic level. Unlike for the large-sized gold nanoparticles $(>3 \mathrm{~nm})$, the method of synthesizing alloy nanoclusters is relatively limited. For instance, galvanic replacement is widely used in the synthesis of alloy nanoclusters. For example, the Ag-Pd alloy nanoparticle could be synthesized by reacting the silver nanoparticle with $\mathrm{Pd}(\mathrm{II})$ salt [3]. However, it is a challenge to synthesize an alloy nanocluster with this method, since the metal nanocluster, which is comprised by active metals, are quite unstable and rarely reported [4].

Previously, the metal exchange method, which uses homo-gold nanoclusters as templates to synthesize alloy nanoclusters, has been reported [5-7]. More importantly, the metal exchange process can jump out of the metal activity sequence, which provides a new way to synthesize the gold nanocluster with a highly active metal (e.g., Cd) [8,9]. So far, two types of metal exchange reactions have been reported: (i) Metal exchange with metal complexes [10-15]. This reaction can be created between thiolated metal complexes (e.g., $\mathrm{Ag}(\mathrm{SR})$ ) and thiolated gold nanoclusters. (ii) Metal exchange between nanoclusters [16-18]. Recently, metal exchange was found between two nanoclusters. Pradeep and co-workers reported the reaction between $\mathrm{Ag}_{25}(\mathrm{SR})_{18}{ }^{-}$and $\mathrm{Au}_{25}(\mathrm{SR})_{18}{ }^{-}$to produce the $\mathrm{Ag}_{\mathrm{x}} \mathrm{Au}_{25-\mathrm{x}}(\mathrm{SR})_{18}{ }^{-}$nanocluster [16]. Based on these two methods, a series of alloy nanoclusters with atomically precise structures have been synthesized; meanwhile, such alloy products have been widely used to study metal synergistic effects in chirality, [19] optics [20,21], and catalysis [22] at the atomic level. It is still necessary to develop new alloying methods, especially a controllable alloying method.

In this work, we reported a third type of metal exchange: self-alloying induced by intramolecular metal exchange. Specifically, the intramolecular metal exchange reaction between $\mathrm{Ag}$ atoms and $\mathrm{Au}$ atoms in the $\mathrm{Ag}_{2} \mathrm{Au}_{25}(\mathrm{SR})_{18}$ nanocluster can occur in the existence of thiol ligands and produce the 
$\mathrm{Ag}_{\mathrm{x}} \mathrm{Au}_{25-\mathrm{x}}(\mathrm{SR})_{18}{ }^{-}$nanocluster. The UV-Vis, thin layer chromatography, and mass spectra indicate the efficient transformation of this self-alloying process.

\section{Materials and Methods}

\subsection{Materials}

Tetrachloroauric(III)acid $\left(\mathrm{HAuCl}_{4} \cdot 3 \mathrm{H}_{2} \mathrm{O},>99.99 \%\right.$ metals basis), silver nitrate $\left(\mathrm{AgNO}_{3}, 99 \%\right.$, metal basis), sodium borohydride $\left(\mathrm{NaBH}_{4}, 99.9 \%\right.$ ), phenylethyl mercaptan (PET, 99\%), tetraoctylammonium bromide (TOABr, $98.0 \%)$, methylene chloride $\left(\mathrm{CH}_{2} \mathrm{Cl}_{2}, \mathrm{HPLC}\right.$ grade), acetonitrile (MeCN, HPLC grade), methanol (MeOH, HPLC grade), and tetrahydrofuran (THF, HPLC grade) were purchased from Sigma-Aldrich (Shanghai, China). Pure water was purchased from Wahaha Co. Ltd., Hangzhou, Zhejiang, China.

\subsection{Synthesis of the $A u_{25}(P E T)_{18}{ }^{-}$Nanocluster}

The synthesis steps were similar to a previously reported process but with minor modifications [23]. $\mathrm{HAuCl}_{4} \cdot 3 \mathrm{H}_{2} \mathrm{O}(0.2 \mathrm{~g} / \mathrm{mL}, 0.4 \mathrm{~mL})$ and TOABr $(0.254 \mathrm{~g}, 0.47 \mathrm{mmol})$ was dissolved in $5 \mathrm{~mL}$ of THF. Then, $400 \mu \mathrm{L}$ ( $2.8 \mathrm{mmol})$ of PET was added to the flask under a slow stirring speed $\sim 60 \mathrm{rpm}$. After the solution turned clear ( $\sim 30 \mathrm{~min})$, the stirring speed was increased to fast $(\sim 1200 \mathrm{rpm})$. At the same time, an aqueous solution of $\mathrm{NaBH}_{4}(0.1550 \mathrm{~g}, 4 \mathrm{mmol})$ was quickly added to the above solution to initiate the reaction. The reaction was allowed to proceed overnight. After that, the solution was washed with $5 \mathrm{~mL}$ pure water. The organic phase was dried via rotoevaporation. $\mathrm{MeOH}(\sim 20 \mathrm{~mL})$ was added to remove the byproducts and this centrifugation cycle was repeated at least 3 times. Then, $10 \mathrm{~mL}$ of $\mathrm{MeCN}$ was used to extract pure $\mathrm{Au}_{25}(\mathrm{PET})_{18}{ }^{-} \mathrm{TOA}^{+}$nanoclusters (NCs).

\subsection{Synthesis of the $A g_{2} A u_{25}(P E T)_{18}{ }^{+}$Nanocluster}

$\mathrm{Ag}_{2} \mathrm{Au}_{25}$ was prepared by modifying a previous method [24]. Briefly, $10 \mathrm{mg}$ of $\mathrm{Au}_{25}(\mathrm{PET})_{18}{ }^{-} \mathrm{TOA}^{+}$ $(1.3 \mu \mathrm{mol}) \mathrm{NCs}$ was dissolved in $10 \mathrm{~mL}$ of $\mathrm{MeCN}$. After that, $0.67 \mathrm{mg}$ of $\mathrm{AgNO}_{3}$ (2.2 equivalents per mole of $\mathrm{Au}_{25}$ ), dissolved in $\mathrm{MeCN}$, was added into the solution. The color of the solution then quickly turned from brown to dark green. The $\mathrm{Ag}_{2} \mathrm{Au}_{25}$ nanocluster was then precipitated out of the solution. $\mathrm{MeCN}(\sim 10 \mathrm{~mL})$ was added to remove the unreacted $\mathrm{AgNO}_{3}$ and other byproducts (e.g., $\mathrm{TOA}^{+} \mathrm{NO}_{3}{ }^{-}$).

\subsection{Intramolecular Metal Exchange of the $\mathrm{Ag}_{2} \mathrm{Au}_{25}$ Nanocluster}

$2 \mathrm{mg}$ of the $\mathrm{Ag}_{2} \mathrm{Au}_{25}$ nanocluster was dissolved in $10 \mathrm{~mL}$ of methylene chloride (DCM). After that, $0.1 \mathrm{~mL}$ PET was added into the solution. The color of the solution slowly turned from green to brown. This reaction was monitored by UV-Vis and MALDI-TOF-MS spectra. After $\sim 70 \mathrm{~min}$, all the $\mathrm{Ag}_{2} \mathrm{Au}_{25}$ nanoclusters were converted into $\mathrm{Ag}_{x} \mathrm{Au}_{25-\mathrm{x}}(\mathrm{SR})_{18}{ }^{-}(\mathrm{x}=0-2)$.

\subsection{Characterization}

All UV-Vis absorption spectra of the nanoclusters dissolved in $\mathrm{CH}_{2} \mathrm{Cl}_{2}$ were recorded using an Agilent 8453 diode array spectrometer (Shanghai China), whose background correction was made using a $\mathrm{CH}_{2} \mathrm{Cl}_{2}$ blank. The X-ray photoelectron spectroscopy (XPS) measurement was performed on a Thermo ESCALAB 250 (Waltham, MA, USA), configured with a monochromated AlK $\alpha(1486.8 \mathrm{eV})$ $150 \mathrm{~W}$ X-ray source, with a $0.5 \mathrm{~mm}$ circular spot size, a flood gun to counter charge the effects, and with the analysis chamber base pressure lower than $1 \times 10^{-9}$ mbar. Inductively coupled plasma-atomic emission spectrometry (ICP-AES) measurements were performed on an Atomscan Advantage instrument made by Thermo Fisher (Waltham, MA, USA). The nanoclusters were digested by concentrated nitric acid and the concentration of the nanoclusters were set to $0.5 \mathrm{mg} \mathrm{L}^{-1}$ approximately. MALDI-TOF-MS was recorded on a Bruker Autoflex III smart beam instrument (Karlsruhe, Germany), using trans-2-[3-(4-tert-butylphenyl)-2-methyl-2-propenylidene] malononitrile (DCTB) as the matrix. 


\section{Results and Discussion}

The $\mathrm{Ag}_{2} \mathrm{Au}_{25}(\mathrm{SR})_{18}$ nanoparticle (Figure 1, abbreviated as $\mathrm{Ag}_{2} \mathrm{Au}_{25}$ hereafter) was made by reaction with the $\mathrm{Au}_{25}(\mathrm{SR})_{18}{ }^{-}$nanocluster, with two equivalents of $\mathrm{AgNO}_{3}$ in acetonitrile. We previously reported that the $\mathrm{Ag}(\mathrm{SR})$ complex reaction with $\mathrm{Au}_{25}(\mathrm{SR})_{18}{ }^{-}$(dissolved in toluene or dichloromethane) will produce the $\mathrm{Ag}_{x} \mathrm{Au}_{25-\mathrm{x}}(\mathrm{SR})_{18}{ }^{-}$nanocluster [6]. However, by using the inorganic $\mathrm{AgNO}_{3}$ instead of $\mathrm{Ag}(\mathrm{SR})$, the silver atoms do not replace the gold atoms in the $\mathrm{Au}_{25}(\mathrm{SR})_{18}{ }^{-}$ nanocluster but, instead, anchor on the surface of the $\mathrm{Au}_{25}$ nanocluster and produce the $\mathrm{Ag}_{2} \mathrm{Au}_{25}$ nanocluster. Interestingly, different kinds of metal salt precursors led to the different alloying result, that is, the metal-exchange or metal adsorption.

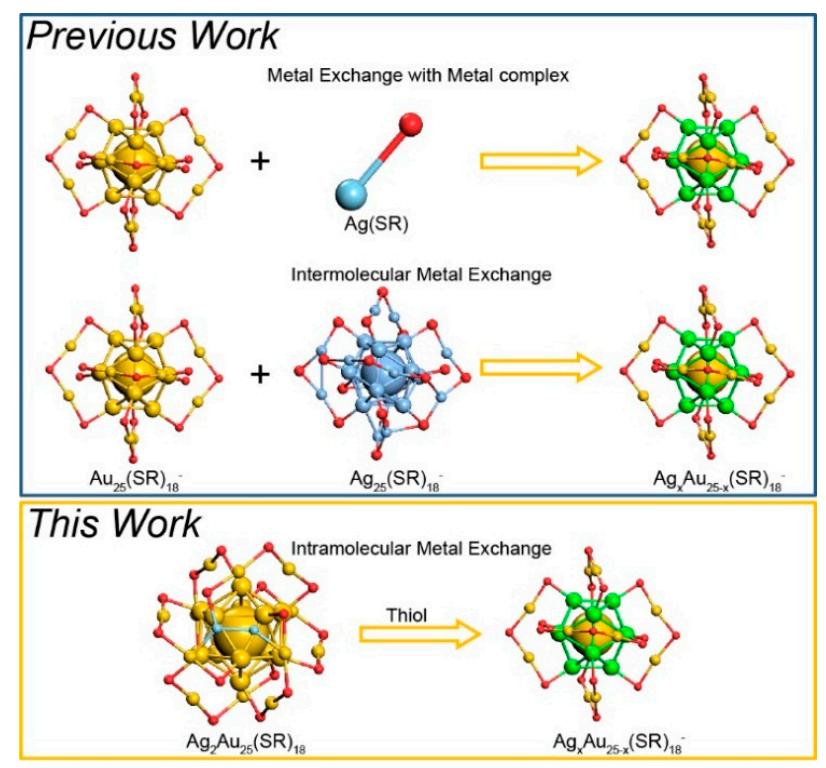

Figure 1. Synthesis of atomically precise alloy nanoclusters with different methods.

We further reacted the $\mathrm{Ag}_{2} \mathrm{Au}_{25}$ with the thiol ligands. And applied the UV-Vis absorption spectra to monitor the reaction process. As shown in Figure 2, the HOMO-LUMO peak at $\sim 700 \mathrm{~nm}$ of $\mathrm{Ag}_{2} \mathrm{Au}_{25}$ gradually blue shifted to $\sim 625 \mathrm{~nm}$. Meanwhile, three absorption points, at $\sim 625 \mathrm{~nm}, \sim 475 \mathrm{~nm}$, and $\sim 410 \mathrm{~nm}$, were found that indicated the quantitative conversion. The final product was determined to be $\mathrm{Ag}_{\mathrm{x}} \mathrm{Au}_{25-\mathrm{x}}(\mathrm{SR})_{18}{ }^{-}$with the $x$ ranging from 0 to 2 (Figure $3 \mathrm{~b}$ ). The metal ratio was further confirmed by the XPS and ICP tests (Table 1 ).

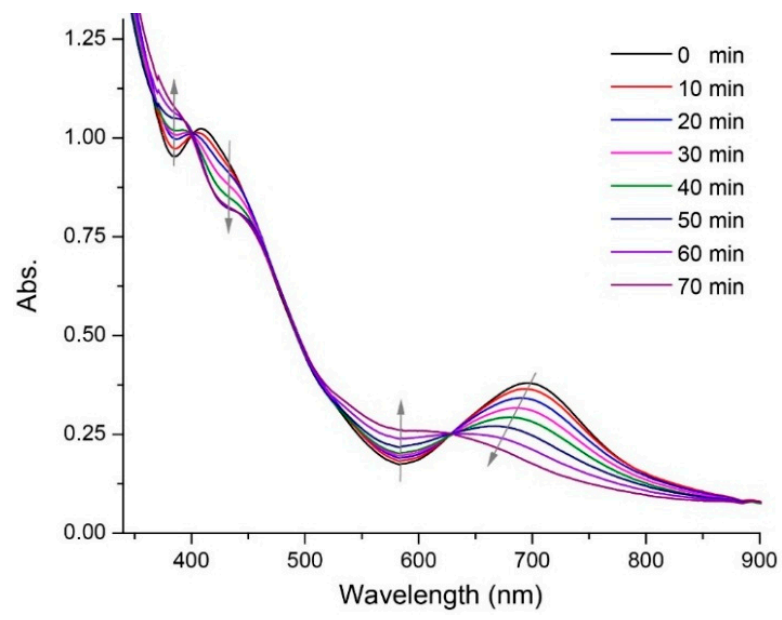

Figure 2. Time-dependent UV-Vis spectra of the $\mathrm{Ag}_{2} \mathrm{Au}_{25}(\mathrm{SR})_{18}$ nanocluster reacting with PET ligands in dichloromethane. 


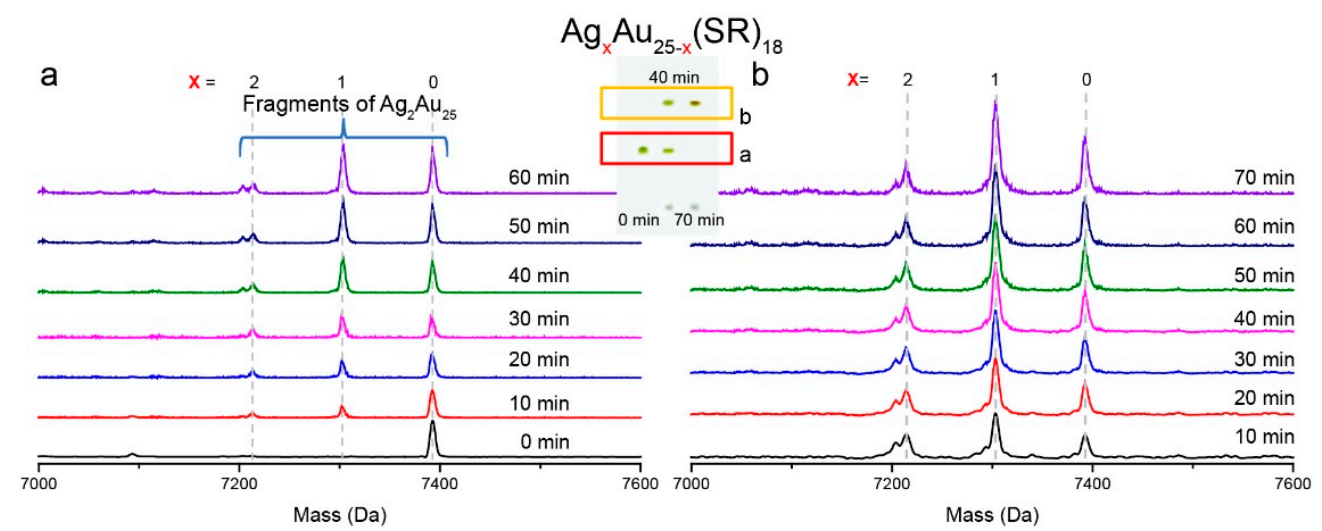

Figure 3. Time-dependent MALDI-TOF-MS spectra of the $\mathrm{Ag}_{2} \mathrm{Au}_{25}(\mathrm{SR})_{18}$ reaction with PET. The inset picture is the Thin-layer chromatography (TLC) of samples at $0 \mathrm{~min}\left(\mathrm{Ag}_{2} \mathrm{Au}_{25}\right), 40 \mathrm{~min}$, and $70 \mathrm{~min}$, respectively. The positive model MALDI-TOF-MS results of the two components separated by TLC are shown in (a) and (b), respectively. Note that, the peaks in (a) are the fragments of $\mathrm{Ag}_{2} \mathrm{Au}_{25}$ according to [24]. The full spectrum of $\mathrm{Ag}_{2} \mathrm{Au}_{25}$ is shown in Figure S1.

Table 1. The atomic ratio of $\mathrm{Au}: \mathrm{Ag}$ in the $\mathrm{Ag}_{\mathrm{x}} \mathrm{Au}_{25-\mathrm{x}}(\mathrm{SR})_{18}{ }^{-}$nanocluster, calculated by Inductively coupled plasma-atomic emission spectrometry (ICP-AES) and X-ray photoelectron spectroscopy (XPS) measurements.

\begin{tabular}{ccc}
\hline Results & Au Atom & Ag Atom \\
\hline ICP experimental ratio & $96.22 \%$ & $3.78 \%$ \\
XPS experimental ratio & $96.04 \%$ & $3.96 \%$ \\
Theoretical & $24 / 25(96 \%)$ & $1 / 25(4 \%)$ \\
\hline
\end{tabular}

Time-dependent TLC and MALDI-TOF-MS spectra were applied to monitor the reaction process (Figure 3). The TLC results showed the high purity of the $\mathrm{Ag}_{2} \mathrm{Au}_{25}$ nanocluster, after addition of the thiol ligands (PET) into the solution, the new compound was formed as demonstrated by the TLC. We further tested the mass spectrum of the two compounds, respectively. The mass spectrum suggested that the molecular ion peak of $\mathrm{Ag}_{2} \mathrm{Au}_{25}$ was not changed, whereas with the different fragment peaks, the pure $\mathrm{Ag}_{2} \mathrm{Au}_{25}$ nanocluster had one fragment peak at $7391 \mathrm{Da}$, which was caused by losing two Ag atoms at the surface. Interestingly, after the addition of the thiol ligands, we found three fragment peaks at $7391 \mathrm{Da}, 7302 \mathrm{Da}$, and $7213 \mathrm{Da}$. The mass difference (89 Da) was equal to the mass difference between $\mathrm{Au}(197 \mathrm{Da})$ and $\mathrm{Ag}(108 \mathrm{Da})$. The different fragmentation after the addition of the thiol ligands suggested that the silver atoms at the surface were exchanged by gold atoms. The new compounds were determined to be $\mathrm{Ag}_{\mathrm{x}} \mathrm{Au}_{25-\mathrm{x}}(\mathrm{SR})_{18}$ nanoclusters, which indicated the occurrence of the metal exchange process.

There are two main approaches in which this metal exchange can occur: (i) In direct metal exchange. In this way, thiol ligands first strip the adsorbed silver ions from the $\mathrm{Ag}_{2} \mathrm{Au}_{25}$ nanocluster. This process results in the $\mathrm{Ag}(\mathrm{SR})$ complex and the $\mathrm{Au}_{25}(\mathrm{SR})_{18}{ }^{-}$nanocluster. Then, metal exchange occurrs between these two products and results in the $\mathrm{Ag}_{x} \mathrm{Au}_{25}(\mathrm{SR})_{18}{ }^{-}$nanocluster. (ii) In intramolecular metal exchange, that is, adsorbed silver ions are exchanged with the kernel gold atoms, which are further stripped by thiol ligands. In order to study this reaction, the mass analysis was applied on the new compounds, which were separated from the TLC. The mass spectra showed similar results during the reaction. The absence of $\mathrm{Ag}_{2} \mathrm{Au}_{25}(\mathrm{SR})_{18}$ indicated this composition had reacted. Three intense peaks, at $7391 \mathrm{Da}, 7302 \mathrm{Da}$, and $7213 \mathrm{Da}$, were found, which were assigned to $\mathrm{Ag}_{2} \mathrm{Au}_{23}, \mathrm{Ag}_{1} \mathrm{Au}_{24}$, and $\mathrm{Au}_{25}$, respectively. It is worth nothing that, the ratio of the three peaks was maintained at 1:2:1 during the reaction. For comparison, we applied the metal exchange reaction between the $\mathrm{Au}_{25}(\mathrm{SR})_{18}{ }^{-}$ nanocluster with the $\mathrm{Ag}(\mathrm{SR})$ complex; the time dependent mass spectra and UV-Vis absorption spectra are shown in Figure S2. Consequently, the intermolecular metal exchange reaction between $\mathrm{Ag}(\mathrm{SR})$ 
with $\mathrm{Au}_{25}(\mathrm{SR})_{18}{ }^{-}$was quite different from the present work. The proportion of doped silver atoms gradually increased with time. These results ruled out the idea that the metal exchange in the $\mathrm{Ag}_{2} \mathrm{Au}_{25}$ nanocluster resulted from the thiol ligand pulling out the adsorbed silver atoms, and the resultant intermolecular metal exchange reaction.

The intramolecular metal exchange in the $\mathrm{Ag}_{2} \mathrm{Au}_{25}$ nanocluster contained two steps (Scheme 1): (i)self-metal-exchange; (ii) metal stripping. In the first step, surface silver atoms exchanged the gold atoms at the kernel, with the promotion of the thiol ligands, and produced the isomeric $\mathrm{Ag}_{2} \mathrm{Au}_{25}$ nanocluster. In the second step, the surface atoms dissociated from the surface of the cluster and produced the $\mathrm{Ag}_{x} \mathrm{Au}_{25-x}$ nanocluster. The 1:2:1 ratio, which was found from the mass spectra of the final product, revealed that the silver to gold ratio was 1:1.

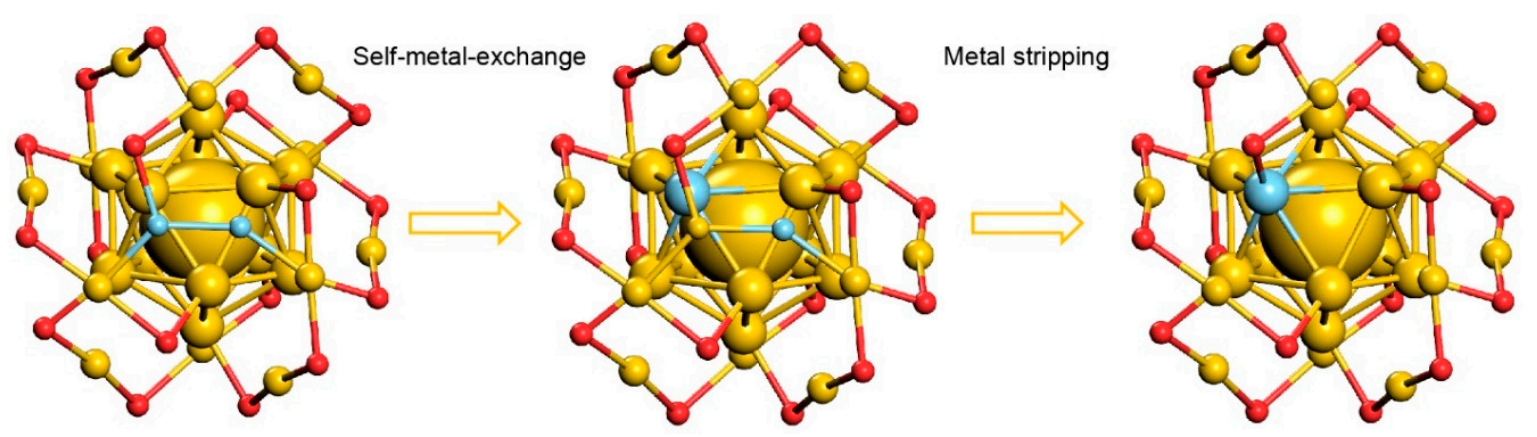

Scheme 1. Th proposed intramolecular metal exchange process.

\section{Conclusions}

In summary, we reported the intramolecular metal exchange in the $\mathrm{Ag}_{2} \mathrm{Au}_{25}$ nanocluster. The intramolecular exchange involves two steps. First, silver atoms at the surface interchange with the gold atoms at the kernel, then the metal ions on the cluster surface are stripped from the cluster. With the intramolecular reaction, we obtained the $\mathrm{Ag}_{x} \mathrm{Au}_{25-\mathrm{x}}(\mathrm{SR})_{18}{ }^{-}(x=0-2)$ nanocluster with a quantitative yield. Our work not only provides a new approach for the metal exchange reaction, but also provides a new perspective for understanding the metal behavior at the nanoscale.

Supplementary Materials: The following are available online at http:/ /www.mdpi.com/2079-4991/8/12/1070/s1, Figure S1: The full spectra of $\mathrm{Ag}_{2} \mathrm{Au}_{25}$ nanocluster with different laser energy during the MALDI-TOF-MS analysis. The intensity of $\mathrm{Au}_{25}$ decreases with the decrease of laser intensity, which indicate the $\mathrm{Au}_{25}$ is the fragment of $\mathrm{Ag}_{2} \mathrm{Au}_{25}$; Figure S2: Time-dependent MALDI-TOF-MS spectra of metal exchange between $\mathrm{Au}_{25}(\mathrm{SR})_{18}{ }^{-}$and $\mathrm{Ag}(\mathrm{SR})$ (4 equivalents) complex. (a) $0 \mathrm{~min}$; (b) $5 \mathrm{~min}$; and (c) $15 \mathrm{~min}$.

Author Contributions: S.W. and M.Z. designed the study; Y.L. and M.C. performed the experiments and analyzed the data. All authors discussed the results and commented on the manuscript.

Funding: This research was funded by NSFC, grant number U1532141, 21631001, 21871001, and 21803001; PhD funding of Anhui University, grant number J10113190012; the Ministry of Education; and the Education Department of Anhui Province and 211 Project of Anhui University.

Conflicts of Interest: The authors declare no conflict of interest.

\section{References}

1. Jin, R.; Zeng, C.; Zhou, M.; Chen, Y. Atomically Precise Colloidal Metal Nanoclusters and Nanoparticles: Fundamentals and Opportunities. Chem. Rev. 2016, 116, 10346-10413. [CrossRef] [PubMed]

2. Chakraborty, I.; Pradeep, T. Atomically Precise Clusters of Noble Metals: Emerging Link between Atoms and Nanoparticles. Chem. Rev. 2017, 117, 8208-8271. [CrossRef] [PubMed]

3. Gilroy, K.D.; Ruditskiy, A.; Peng, H.-C.; Qin, D.; Xia, Y. Bimetallic Nanocrystals: Syntheses, Properties, and Applications. Chem. Rev. 2016, 116, 10414-10472. [CrossRef] [PubMed]

4. Nguyen, T.D.; Jones, Z.R.; Goldsmith, B.R.; Buratto, W.R.; Wu, G.; Scott, S.L.; Hayton, T.W. A Cu 25 Nanocluster with Partial Cu(0) Character. J. Am. Chem. Soc. 2015, 137, 13319-13324. [CrossRef] [PubMed] 
5. Wang, S.; Li, Q.; Kang, X.; Zhu, M. Customizing the Structure, Composition, and Properties of Alloy Nanoclusters by Metal Exchange. Acc. Chem. Res. 2018, 51, 2784-2792. [CrossRef] [PubMed]

6. Wang, S.; Song, Y.; Jin, S.; Liu, X.; Zhang, J.; Pei, Y.; Meng, X.; Chen, M.; Li, P.; Zhu, M. Metal Exchange Method Using $\mathrm{Au}_{25}$ Nanoclusters as Templates for Alloy Nanoclusters with Atomic Precision. J. Am. Chem. Soc. 2015, 137, 4018-4021. [CrossRef]

7. Wang, S.; Abroshan, H.; Liu, C.; Luo, T.-Y.; Zhu, M.; Kim, H.J.; Rosi, N.L.; Jin, R. Shuttling single metal atom into and out of a metal nanoparticle. Nat. Commun. 2017, 8, 848. [CrossRef]

8. Yang, S.; Wang, S.; Jin, S.; Chen, S.; Sheng, H.; Zhu, M. A metal exchange method for thiolate-protected tri-metal $\mathrm{M}_{1} \mathrm{Ag}_{x} \mathrm{Au}_{24-\mathrm{x}}(\mathrm{SR})_{18}(\mathrm{M}=\mathrm{Cd} / \mathrm{Hg})$ nanoclusters. Nanoscale 2015, 7, 10005-10007. [CrossRef]

9. Yang, S.; Chen, S.; Xiong, L.; Liu, C.; Yu, H.; Wang, S.; Rosi, N.L.; Pei, Y.; Zhu, M. Total Structure Determination of $\mathrm{Au}_{16}(\mathrm{~S}-\mathrm{Adm})_{12}$ and $\mathrm{Cd}_{1} \mathrm{Au}_{14}(\mathrm{StBu})_{12}$ and Implications for the Structure of $\mathrm{Au}_{15}(\mathrm{SR})_{13}$. J. Am. Chem. Soc. 2018, 140, 10988-10994. [CrossRef]

10. Jin, S.; Du, W.; Wang, S.; Kang, X.; Chen, M.; Hu, D.; Chen, S.; Zou, X.; Sun, G.; Zhu, M. Thiol-Induced Synthesis of PhosphineProtected Gold Nanoclusters with Atomic Precision and Controlling the Structure by Ligand/Metal Engineering. Inorg. Chem. 2017, 56, 11151-11159. [CrossRef]

11. Li, Q.; Lambright, K.J.; Taylor, M.G.; Kirschbaum, K.; Luo, T.-Y.; Zhao, J.; Mpourmpakis, G.; Mokashi-Punekar, S.; Rosi, N.L.; Jin, R. Reconstructing the Surface of Gold Nanoclusters by Cadmium Doping. J. Am. Chem. Soc. 2017, 139, 17779-17782. [CrossRef]

12. Li, Q.; Wang, S.; Kirschbaum, K.; Lambright, K.J.; Das, A.; Jin, R. Heavily doped $\mathrm{Au}_{25-x} \mathrm{Ag}_{\mathrm{x}}\left(\mathrm{SC}_{6} \mathrm{H}_{11}\right)_{18}$ nanoclusters: Silver goes from the core to the surface. Chem. Commun. 2016, 52, 5194-5197. [CrossRef]

13. Du, W.; Jin, S.; Xiong, L.; Chen, M.; Zhang, J.; Zou, X.; Pei, Y.; Wang, S.; Zhu, M. Ag (Do $_{5 p m}$ (DR $_{30}$ and Its Homologue $\mathrm{Au}_{x} \mathrm{Ag}_{50-x}(\mathrm{Dppm})_{6}(\mathrm{SR})_{30}$ Alloy Nanocluster: Seeded Growth, Structure Determination, and Differences in Properties. J. Am. Chem. Soc. 2017, 139, 1618-1624. [CrossRef]

14. Kang, X.; Xiong, L.; Wang, S.; Yu, H.; Jin, S.; Song, Y.; Chen, T.; Zheng, L.; Pan, C.; Pei, Y.; et al. ShapeControlled Synthesis of Trimetallic Nanoclusters: Structure Elucidation and Properties Investigation. Chem. Eur. J. 2016, 22, 17145-17150. [CrossRef] [PubMed]

15. Hossain, S.; Ono, T.; Yoshioka, M.; Hu, G.; Hosoi, M.; Chen, Z.; Nair, L.V.; Niihori, Y.; Kurashige, W.; Jiang, D.-E.; et al. Thiolate-Protected Trimetallic $\mathrm{Au}_{\sim 20} \mathrm{Ag}_{\sim 4} \mathrm{Pd}$ and $\mathrm{Au}_{\sim 20} \mathrm{Ag}_{\sim 4} \mathrm{Pt}$ Alloy Clusters with Controlled Chemical Composition and Metal Positions. J. Phys. Chem. Lett. 2018, 9, 2590-2594. [CrossRef] [PubMed]

16. Krishnadas, K.R.; Baksi, A.; Ghosh, A.; Natarajan, G.; Pradeep, T. Structure-conserving spontaneous transformations between nanoparticles. Nat. Commun. 2016, 7, 13447. [CrossRef]

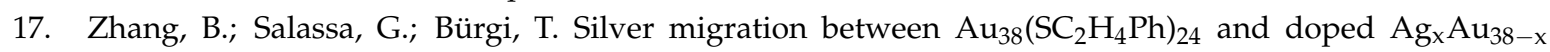
$\left(\mathrm{SC}_{2} \mathrm{H}_{4} \mathrm{Ph}\right)_{24}$ nanoclusters. Chem. Commun. 2016, 52, 9205-9207. [CrossRef]

18. Zhang, B.; Safonova, O.V.; Pollitt, S.; Salassa, G.; Sels, A.; Kazan, R.; Wang, Y.; Rupprechter, G.; Barrabes, N.; Bürgi, T. On the mechanism of rapid metal exchange between thiolate-protected gold and gold/silver clusters: A time-resolved in situ XAFS study. Phys. Chem. Chem. Phys. 2018, 20, 5312-5318. [CrossRef] [PubMed]

19. Zhang, B.; Bürgi, T. Doping Silver Increases the $\mathrm{Au}_{38}(\mathrm{SR})_{24}$ Cluster Surface Flexibility. J. Phys. Chem. C 2016, 120, 4660-4666. [CrossRef]

20. Wang, S.; Meng, X.; Das, A.; Li, T.; Song, Y.; Cao, T.; Zhu, X.; Zhu, M.; Jin, R. A 200-fold Quantum Yield Boost in the Photoluminescence of Silver Doped $\mathrm{Ag}_{x} \mathrm{Au}_{25-\mathrm{x}}$ Nanoclusters: The 13th Silver Atom Matters. Angew. Chem. Int. Ed. 2014, 53, 2376-2380. [CrossRef]

21. Bootharaju, M.S.; Joshi, C.P.; Parida, M.R.; Mohammed, O.F.; Bakr, O.M. Templated Atom-Precise Galvanic Synthesis and Structure Elucidation of a $\left[\mathrm{Ag}_{24} \mathrm{Au}(\mathrm{SR})_{18}\right]^{-}$Nanocluster. Angew. Chem. 2016, 128, 934-938. [CrossRef]

22. Deng, H.; Wang, S.; Jin, S.; Yang, S.; Xu, Y.; Liu, L.; Xiang, J.; Hu, D.; Zhu, M. Active metal (cadmium) doping enhanced the stability of inert metal (gold) nanocluster under $\mathrm{O}_{2}$ atmosphere and the catalysis activity of benzyl alcohol oxidation. Gold Bull. 2015, 48, 161-167. [CrossRef] 
23. Parker, J.F.; Weaver, J.E.F.; McCallum, F.; Fields-Zinna, C.A.; Murray, R.W. Synthesis of Monodisperse $\left[\mathrm{Oct}_{4} \mathrm{~N}\right]^{+}\left[\mathrm{Au}_{25}(\mathrm{SR})_{18}\right]^{-}$Nanoparticles, with Some Mechanistic Observations. Langmuir 2010, 26, 13650-13654. [CrossRef]

24. Yao, C.; Chen, J.; Li, M.; Liu, L.; Yang, J.; Wu, Z. Adding Two Active Silver Atoms on Au 25 Nanoparticle. Nano Lett. 2015, 15, 1281-1287. [CrossRef] [PubMed]

(c)

(C) 2018 by the authors. Licensee MDPI, Basel, Switzerland. This article is an open access article distributed under the terms and conditions of the Creative Commons Attribution (CC BY) license (http:/ / creativecommons.org/licenses/by/4.0/). 